\title{
Online Professionalism-2018 Update of European Association of Urology (@Uroweb) Recommendations on the Appropriate Use of Social Media
}

\author{
Hendrik Borgmann $^{a, *}$, Matthew Cooperberg ${ }^{b}$, Declan Murphy $^{c, d}$, Stacy Loeb $^{e, f}$, James $^{\text {'Dow }}{ }^{g}$, \\ Maria Jose Ribal ${ }^{h}$, Henry Woo ${ }^{i, j}$, Morgan Rouprêt ${ }^{k}$, Andrew Winterbottom ${ }^{l}$, Carl Wijburg ${ }^{m}$, \\ Manfred Wirth ${ }^{n}$, James Catto $^{o}$, Alexander Kutikov ${ }^{p}$ \\ ${ }^{a}$ Department of Urology, University Medicine Johannes Gutenberg-University Mainz, Mainz, Germany; ${ }^{\mathrm{b}}$ Department of Urology, University of California, San \\ Francisco, San Francisco, CA, USA; ${ }^{\mathrm{c}}$ Division of Cancer Surgery, Peter MacCallum Cancer Centre, Melbourne, Australia; ${ }^{\mathrm{d}}$ The Sir Peter MacCallum Department

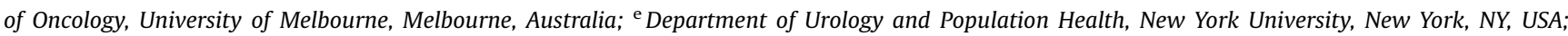 \\ ${ }^{\mathrm{f}}$ Manhattan Veterans Affairs Medical Center, New York, NY, USA; ${ }^{\mathrm{g}}$ Academic Urology Unit, University of Aberdeen, Aberdeen, Scotland, UK; ${ }^{\mathrm{h}}$ Department of \\ Urology, Hospital Clinic, University of Barcelona, Spain; ${ }^{i}$ Sydney Adventist Hospital Clinical School, University of Sydney, NSW, Australia; ${ }^{j}$ Department of \\ Uro-Oncology, Chris O'Brien Lifehouse, NSW, Australia; ${ }^{k}$ Academic Department of Urology, La Pitié-Salpétrière Hospital, Assistance-Publique Hôpitaux de \\ Paris, Paris, France; ${ }^{1}$ Fight Bladder Cancer, Oxfordshire, UK; ${ }^{\mathrm{m}}$ Department of Urology, Robotic Surgery, Rijnstate Hospital, Arnhem, The Netherlands; \\ ${ }^{\mathrm{n}}$ Department of Urology, University Hospital Carl Gustav Carus, Technische Universität Dresden, Dresden, Germany; ${ }^{\circ}$ Academic Urology Unit, University of \\ Sheffield, Sheffield, UK; ${ }^{\mathrm{P}}$ Division of Urologic Oncology, Fox Chase Cancer Center, Temple University Health System, Philadelphia, PA, USA
}

Keywords:

Digitalization

Digital media

Facebook

Guidelines

Instagram

Professionalism

Social media

Twitter

YouTube

WhatsApp

\begin{abstract}
Context: Social media (SoMe) has transformed communication among health care professionals by enabling rapid and global information exchange. Yet, the novelty of SoMe and concerns about potential risks continue to be barriers to adoption.

Objective: To encourage appropriate professional use of SoMe by physicians in concordance with best practices and to update practical guidelines for effective and professional use of these communication technologies.

Evidence aquisition: The European Association of Urology (EAU; @Uroweb) brought together a committee of SoMe stakeholders in the urology field. PubMed and the grey literature were searched to identify SoMe position papers by other medical societies and organizations. Evidence synthesis: Updated practical guidelines for effective and professional use of SoMe communication technologies. A core of 10 practical recommendations for the responsible, ethical, and constructive use of SoMe communication technologies was articulated. The guidelines are limited by their inherent subjective nature and lack of robust evidence supporting their utility.

Conclusions: SoMe is reshaping the way the urological care providers communicate; however, appropriate engagement requires courtesy, professionalism, and honesty. Adherence to guidelines will help users harness the benefits of SoMe in a safe and effective manner.

Patient summary: Social media has transformed communication among health care professionals. This narrative review article provides an update of practical guidelines for effective and professional use of these communication technologies.
\end{abstract}

\footnotetext{
* Corresponding author. Department of Urology, University Medicine Johannes Gutenberg-University Mainz, 55131 Mainz, Germany. Tel. +49-176-61502875; Fax: +49-6131-17-2305.

E-mail address: hendrik.borgmann@unimedizin-mainz.de (H. Borgmann).
} 


\section{Introduction}

Social media (SoMe) is defined as digital technologies that facilitate the conception and sharing of information, ideas, career interests, and other forms of expression via virtual communities and networks [1]. The offering of SoMe platforms is continuously expanding and evolving. The field of urology has been at the forefront of the SoMe revolution and has embraced its tremendous potential [2]. Yet, significant barriers to adoption and full utilization of SoMe exist, largely stemming from real and perceived risks of SoMe use [3]. The unstructured and unscripted nature of SoMe may prevent some members of the urologic community from fully recognizing and harnessing its benefits. To mitigate the risks of unprofessional conduct using SoMe and to encourage appropriate use, the European Association of Urology (EAU; @Uroweb) convened a committee of stakeholders to update and expand on previously published practical guidelines for the use of publically available communication technologies in an effective and ethical manner [4,5].

\section{Evidence aquisition}

A PubMed search was performed for the keywords "social media" AND "recommendations" OR "guidelines" OR "best practice" to identify SoMe position papers by other medical societies and organizations. Additionally, a search of the grey literature on the Google search engine was performed to identify additional statements by societies. Our search yielded 1439 results. Using a step-wise approach, titles, abstracts, and full texts of all manuscripts were screened by two authors (H.B. and A.K.) for inclusion in this review. Based on the 12 studies included, 10 core practical recommendations for the responsible, ethical, and constructive use of SoMe communication technologies were drafted, vetted by co-authors, and revised until a consensus was reached.

\section{Evidence synthesis}

\subsection{Current SoMe landscape}

The number of global SoMe users has steadily grown from 1 billion in 2010 to some 2.77 billion users in 2018. Indeed, the current annual growth rate for SoMe users is approximately $13 \%$ per year [6]. The main SoMe platforms utilized by physicians in 2018 are summarized in Table 1; however, the Twitter platform has been the lynchpin of professional information exchange amongst urologists.

Twitter is a social networking and microblogging online service that allows users to post messages called tweets with a limited set of characters (previously 140, but recently expanded to 280). Twitter has 328 million users worldwide, and user rates among urologists are as high as 48\% [7]. The urological community has experienced a dramatic rise in Twitter use, employed for rapid informal information exchange, remote and augmented conference experience during urological meetings, and for conducting asynchronous virtual journal clubs [8-11]. Moreover, academic journals are increasingly harnessing Twitter to engage the medical community. A significant association between Twitter presence and journal impact factor has been reported [12,13].

\subsection{Deliverables of SoMe-how physicians benefit}

There are a number of compelling reasons for busy practicing physicians to familiarize themselves with professional use of SoMe. Urologists who were early adopters of SoMe report various benefits of SoMe including professional networking, information exchange, career development, and advocacy [20]. Practical applications for SoMe in urology on both Twitter and other platforms include the following:

\subsubsection{Information filtering and curated consumption}

SoMe allows rapid real-time interactions between stakeholders in the health care sector [37]. As such, one's personal SoMe stream can be tailored to receive personalized content from news outlets, medical journals, professional societies, and key opinion leaders. Academic journals are increasingly harnessing SoMe to engage the medical community [5,36]. A significant association between Twitter presence and journal impact factor has been reported [12,13,38]. The EAU Guidelines Office Dissemination Committee has used SoMe to publicize clinical guidelines by posting specifically designed posts, and guideline adherence has been evaluated in real-time by using SoMebased polls [21]. Furthermore, by following key opinion leaders who have an active SoMe presence, users can enjoy an up-to-date, curated, and contextualized content stream. Furthermore, Twitter has been used to crowdsource and apply management strategies for complex urologic patients [11] and to hold multiple regular journal clubs on urology and various subspecialities, including pediatric urology, prostate cancer, and sexual medicine [19]. Besides these SoMe platforms, blogs are a relevant source of information on timely topics. Platforms such as Wordpress and Blogger have a very large audience and are also used as a mechanism for information exchange for a number of urologists [39].

\subsubsection{Augmented and remote conference experience}

The urological community has enthusiastically adopted the use of Twitter during conferences, allowing for an "augmented" experience for those in attendance and remote participation for those unable to be physically present at a particular meeting $[8,40]$. Through the use of meeting hashtags, SoMe content is earmarked so that users can easily identify and follow content streams related to a particular event. In this way, individuals who are following the meeting remotely (even from other continents) can engage and exchange ideas with those who are physically present at the meeting itself. Meanwhile, those who attend the meeting can be "virtually present" at more than one location by following appropriate SoMe streams. This mechanism catalyzes a rich exchange of ideas, insights, 
Table 1 - Popular social media platforms and their characteristics

\begin{tabular}{|c|c|c|c|c|c|c|}
\hline Platform & $\begin{array}{l}\text { Year of } \\
\text { platform } \\
\text { launch }\end{array}$ & $\begin{array}{c}\text { Platform } \\
\text { differentiator }\end{array}$ & Privacy features & $\begin{array}{l}\text { Number of } \\
\text { users }\end{array}$ & Use in medicine & $\begin{array}{l}\text { Documented use in } \\
\text { urology }\end{array}$ \\
\hline Twitter & 2006 & $\begin{array}{l}\text { A social networking } \\
\text { and microblogging } \\
\text { online service that } \\
\text { allows users to send } \\
\text { and receive text-based } \\
\text { messages or posts of up } \\
\text { to } 280 \text { characters } \\
\text { called tweets }\end{array}$ & $\begin{array}{l}\text { Largely entirely public } \\
\text { (private settings are } \\
\text { also available) }\end{array}$ & 330 million & $\begin{array}{l}\text { Online journal clubs [9] } \\
\text { Patient online support [14] } \\
\text { Discussions about clinical } \\
\text { care [11] } \\
\text { Specific disease } \\
\text { information exchange [15] } \\
\text { Research [16] } \\
\text { Policy discussions [17] }\end{array}$ & $\begin{array}{l}\text { Augmented conference } \\
\text { experience [8] } \\
\text { Information dissemination } \\
\text { by journals [18] } \\
\text { Urological online journal } \\
\text { clubs [19] } \\
\text { Potentiating professional } \\
\text { goals [20] } \\
\text { Disseminating and } \\
\text { evaluating clinical guidelines } \\
\text { [21] } \\
\text { Twitter impact factor [12] } \\
\text { Research [20] } \\
\text { Clinical crowdsourcing [11] }\end{array}$ \\
\hline Facebook & 2004 & $\begin{array}{l}\text { Popular social } \\
\text { networking website } \\
\text { that allows registered } \\
\text { users to create profiles, } \\
\text { upload photos and } \\
\text { videos, send messages } \\
\text { and keep in touch with } \\
\text { friends, family, and } \\
\text { colleagues }\end{array}$ & $\begin{array}{l}\text { Granular toggling of } \\
\text { privacy features is } \\
\text { possible }\end{array}$ & 2.2 billion & $\begin{array}{l}\text { Physicians Group Networks } \\
\text { [22] } \\
\text { Recruitment for clinical } \\
\text { trials [23] }\end{array}$ & $\begin{array}{l}\text { Dissemination of information } \\
\text { for patient awareness } \\
\text { campaigns [24] } \\
\text { Exposure of potentially } \\
\text { unprofessional personal } \\
\text { behavior to the public [25] }\end{array}$ \\
\hline YouTube & 2005 & $\begin{array}{l}\text { Video-sharing website } \\
\text { that allows users to } \\
\text { upload, view, and } \\
\text { interact with videos, } \\
\text { and to follow other } \\
\text { users' content }\end{array}$ & $\begin{array}{l}\text { Largely public; } \\
\text { however, private } \\
\text { interphase is available. }\end{array}$ & 1.5 billion & $\begin{array}{l}\text { Patient and physician } \\
\text { education } \\
\text { Promotional content } \\
\text { dissemination }\end{array}$ & $\begin{array}{l}\text { Public education [26] } \\
\text { Quantification of public } \\
\text { interest in diseases and } \\
\text { treatments in the urology } \\
\text { space [27] }\end{array}$ \\
\hline LinkedIn & 2003 & $\begin{array}{l}\text { Business- and } \\
\text { employment-oriented } \\
\text { service mainly focused } \\
\text { on professional } \\
\text { networking }\end{array}$ & Public & 530 million & $\begin{array}{l}\text { Continuing professional } \\
\text { development [28] }\end{array}$ & $\begin{array}{l}\text { Most highly used platform } \\
\text { for professional networking } \\
{[29,30]}\end{array}$ \\
\hline Instagram & 2010 & $\begin{array}{l}\text { Service that allows } \\
\text { users to share photos } \\
\text { and videos }\end{array}$ & $\begin{array}{l}\text { Both private and public } \\
\text { accounts are possible }\end{array}$ & 800 million & $\begin{array}{l}\text { Plastic surgery education } \\
\text { and marketing [31] }\end{array}$ & $\begin{array}{l}\text { Up to } 5 \text { million impressions } \\
\text { for "prostate cancer" in a } 1 \text { - } \\
\text { mo time period [26] }\end{array}$ \\
\hline Snapchat & 2011 & $\begin{array}{l}\text { Image messaging and } \\
\text { multimedia mobile } \\
\text { application }\end{array}$ & Largely private & 187 million & $\begin{array}{l}\text { Has been used in } \\
\text { emergency setting to } \\
\text { identify, provide context, } \\
\text { and affect treatment for a } \\
\text { toxic ingestion [32] }\end{array}$ & $\begin{array}{l}\text { None documented in the } \\
\text { literature }\end{array}$ \\
\hline WhatsApp & 2009 & $\begin{array}{l}\text { Cross-platform instant } \\
\text { messaging and Voice } \\
\text { over IP service }\end{array}$ & Private & 1.3 billion & $\begin{array}{l}\text { Simple, cheap, and } \\
\text { effective means of } \\
\text { communication within the } \\
\text { clinical health sector [33] }\end{array}$ & $\begin{array}{l}\text { Evaluation of degree of } \\
\text { hematuria [34] }\end{array}$ \\
\hline WeChat & 2011 & $\begin{array}{l}\text { Instant messaging, } \\
\text { payment services, } \\
\text { games }\end{array}$ & Private & $\begin{array}{l}>1 \text { billion } \\
\text { monthly users }\end{array}$ & $\begin{array}{l}\text { The most popular social } \\
\text { media platform in China }\end{array}$ & $\begin{array}{l}\text { Widely used among } \\
\text { physicians for continuing } \\
\text { medical education including } \\
\text { conference streaming [35] }\end{array}$ \\
\hline Google+ & 2011 & $\begin{array}{l}\text { Social media network } \\
\text { launched by Google } \\
\text { that recently has seen } \\
\text { declining user } \\
\text { engagement }\end{array}$ & Public & 111 million & $\begin{array}{l}\text { None documented in the } \\
\text { literature }\end{array}$ & $\begin{array}{l}\text { Used by journals to } \\
\text { disseminate content [36] }\end{array}$ \\
\hline Doximity & 2011 & $\begin{array}{l}\text { Online social } \\
\text { networking service for } \\
\text { US clinicians, nurse } \\
\text { practitioners, physician } \\
\text { assistants, and } \\
\text { pharmacists }\end{array}$ & $\begin{array}{l}\text { Only available to US } \\
\text { health care } \\
\text { professionals }\end{array}$ & 1 million & $\begin{array}{l}\text { Eg, Residency navigator: a } \\
\text { tool to help medical } \\
\text { students find residency } \\
\text { programs that fit their } \\
\text { professional needs based } \\
\text { on user-submitted } \\
\text { evaluations }\end{array}$ & $\begin{array}{l}\text { None documented in the } \\
\text { literature }\end{array}$ \\
\hline Sermo & 2005 & $\begin{array}{l}\text { Private social media } \\
\text { network limited to } \\
\text { physicians }\end{array}$ & Private & 800000 & $\begin{array}{l}\text { Crowdsourcing patient } \\
\text { case discussions }\end{array}$ & $\begin{array}{l}\text { None documented in the } \\
\text { literature }\end{array}$ \\
\hline
\end{tabular}


and expertise around the particular meeting's content even after the meeting is adjourned.

\subsubsection{Academic research}

The value of SoMe in advancing surgical research largely stems from lowering barriers for connecting investigators with common interests, enabling patient recruitment for clinical trials or engagement with patient-reported outcome research [41], and even providing a source of primary data for research [17]. Indeed, SoMe manuscripts in urology have been heavily cited (a mean of 16.3 times in the 2-yr time period after publication), with most citations occurring in journals outside of the urology space [42].

\subsubsection{Educational tool}

Organizations, societies, and journals have adopted SoMe as complementary means to enhance education of urologic providers and patients. A recent survey of young urologists in Europe demonstrated that SoMe plays a significant role in knowledge acquisition [30]. Notably, YouTube ranked as a primary source for educational videos on surgical procedures for this cohort of young European urologists. It is important to emphasize that much of this content is not peer-reviewed and may contain biases. Thus, such content should be considered with some caution. Furthermore, many journals and societies have created patient-facing accounts to potentiate information regarding urologic health. There have been numerous public-facing tweet chats to raise awareness and provide information about urologic diseases.

\subsubsection{Profession campaigns}

A recent \#ILookLikeASurgeon online campaign promoting diversity and gender equality in surgery has engaged over 35000 Twitter users in over 150000 tweets, resulting in nearly a billion impressions [43]. The campaign was embraced by urology, adopting the hashtag \#ILookLikeAUrologist. Initiated in 2015, urologists from around the world have joined this campaign to celebrate diversity and gender equality. Until now, \#ILookLikeAUrologist accounts for 2561 tweets by 942 users, leading to more than 5 million impressions (data provided by symplur.com)

\subsubsection{Structured communication}

The Urology Tag Ontology, a hashtag list comprising 45 hashtags in nine urologic subspecialities, has been introduced for standardizing content descriptor use in the urologic SoMe community and to facilitate communication and collaboration between health care provider and patient stakeholders [44]. This effort has afforded high-fidelity assessment and indexing of activity, user details, and content type of urology-related Twitter traffic [45].

\subsection{EAU's (@Uroweb) recommendations on the appropriate use of SoMe}

The EAU brought together a group of SoMe users and stakeholders to update a set of guidelines for optimal professional SoMe use that was originally compiled and published in 2014 [4]. Guidelines for appropriate use of SoMe are necessary since unprofessional SoMe conduct has significant risks. A recent analysis of US urology residency graduates' Facebook accounts revealed that a substantial proportion contained self-authored unprofessional content [25]. The open nature of SoMe lends itself to the perils of violating patient privacy and undermining other professional conduct norms. Based on information gathered through our previously described literature review, stakeholder input, and the previously published @Uroweb 2014 guidelines on the appropriate use of SoMe [4], the guidelines were updated. A core of 10 practical recommendations (Fig. 1) for the responsible, ethical, and constructive use of SoMe communication technologies was articulated.

3.3.1. Never undermine your patients' privacy and confidentiality Information posted to SoMe platforms is generally entirely public and permanent. The same expectations of patient confidentiality and Health Insurance Portability and Accountability Act (HIPAA) compliance that exist offline apply to online behavior. Violation of patient privacy is perhaps the biggest potential pitfall of professional SoMe. Users must avoid direct patient identification and must refrain from showing images or sharing patient care details that could lead to an individual's identification. Sharing of videos must also be done with great care. Thorough review of each video must verify that no frame undermines patient privacy.

3.3.2. Understand how other users behave online before interacting on social networks

When starting to use SoMe, it is beneficial to begin as a "passive user" or follower for a period of time in order to observe and understand SoMe interactions and to develop an appreciation of each platform's etiquette.

\subsubsection{Establish a professional digital identity that is in line with} your professional practice and goals

When setting up a professional SoMe account, state clearly who you are, what your profession is, and in what role you plan to interact with SoMe. It is advisable to use your real name and a professional photo. Many users list their employer, but indicate that the account represents the user's own opinions. Periodic self-audits of your online presence are prudent as one's professional digital footprint is a constant reflection of one's professional health [46].

3.3.4. Avoid providing medical advice and maintain limits between yourself and patients

Do not engage in exchanges that may be misinterpreted as patient-physician relationships. Avoid providing specific medical advice. Patients and caregivers will understandably seek out physicians on SoMe platforms for their input; albeit current SoMe etiquette has made such interactions infrequent. If contacted by a patient or family member, it is best to refer the patient to legitimate sources of information that are already available online. Recommending that a patient make a formal appointment with a specialist or a general practitioner to discuss a particular case is often 


\section{EAU's Recommendations on the Appropriate Use of Social Media}

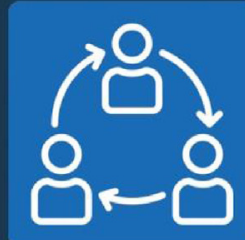

Understand how other users behave online before interacting on social networks

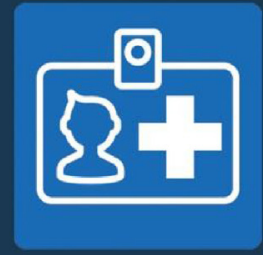

Establish and maintain a professional digital identity that is in line with your professional practice and goals

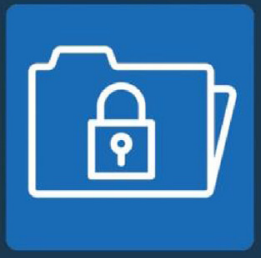

Never undermine your patients' privacy or confidentiality

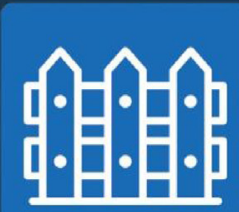

Avoid providing medical advice and maintain limits between yourself and patients

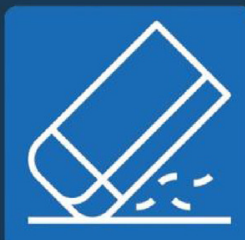

Assume that anything and everything you post is permanent

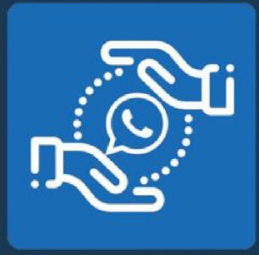

Use Instant Messaging services with care

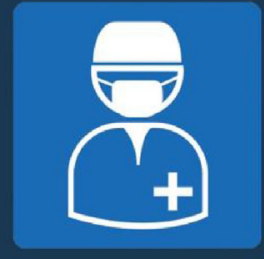

Exercise professionalism

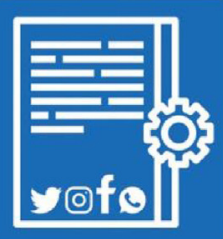

Beware of social media policies set by employers

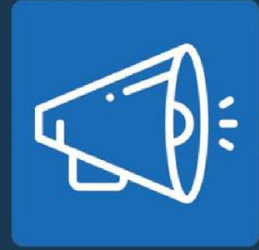

Beware of how advertisement and self-promotion will be perceived by others

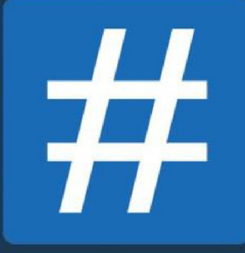

Use disease-specific ontology hashtags for structured online communication

Fig. 1 - Ten practical recommendations for ethical, professional, and effective social media use. EAU = European Association of Urology.

most appropriate. Befriending patients on one's personal SoMe accounts is not recommended.

3.3.5. Assume that anything and everything you post is permanent Be aware that all content posted online, even that which has been "deleted", will likely remain publically available in perpetuity. Any content posted to a SoMe site holds potential to be disseminated far beyond the originally intended audience. Quotes, photos, and commentary can be taken out of context and reposted elsewhere, despite privacy settings. The "golden rule" is a "pause-beforeposting" practice. Never post on impulse or when your judgment may be clouded. All SoMe posts are timestamped; therefore, be sure not to post during critical clinical encounters (eg, when in the operating room), so that a SoMe post cannot be misinterpreted as a distraction. Any level of data contained on SoMe platforms, regardless of security settings, should be regarded as potentially accessible.

\subsubsection{Use instant messaging services with care}

Some institutions, especially those in the United States, only allow patient information exchange through specifically-licensed HIPAA compliant software. Ensure that you 
know your institution's policy before sharing patient information with others through publically-available messaging software. Importantly, use great caution in exchanging protected health information or providing medical consultations over non-secure networks. The instant messenger service, WhatsApp, provides several useful functions for the health care sector such as educating students/residents/patients and facilitating communication about patient care among staff groups. Although communications including text messages, calls, and media are protected from interception by all parties except the sender and receiver by an end-to-end encryption protocol, patient information needs to be anonymized and use of a particular platform must be approved by the user's institution. Settings for group discussions that potentially contain patient-related data should be modified by toggling the setting for "save incoming media" to "no". This avoids unauthorized view of patient-related data in case your phone is in use by another person or is lost or stolen.

\subsubsection{Exercise professionalism}

Always consider your content in the context of appropriate professional opinions, views, and standards. Be honest and courteous. While it is acceptable to disagree with colleagues via SoMe, such messages should be respectful, collegial, and reflect positively on the profession. Avoid defamatory and personal comments that violate professional norms. Reach out to colleagues whose SoMe conduct may be unprofessional or inappropriate.

\subsubsection{Beware of social media policies set by employers}

Some institutions have created SoMe policies that may set limits on one's ability to post publically to SoMe platform. One should review any SoMe policies created by one's institution in order to stay in compliance with such policies. Some employers require that health care providers explicitly state that the views expressed on SoMe do not represent those of their institution by indicating in their profile that "views are my own".

\subsubsection{Beware of how advertisement and self-promotion is perceived} by others

Remember your professional obligations to offer sound opinions and to report factually correct data. Do not make claims that cannot be substantiated or verified, and do not advertise your services or results beyond medically verifiable data. Online discussions or posts which could be associated with financial conflicts of interest must be transparent.

3.3.10. Use disease-specific ontology hashtags for structured online communication

Urology is one of the first specialties to create the "Urology Tag Ontology," which is a listing of urology-related hashtags designed to standardize SoMe communication descriptor use [44]. The Urology Tag Ontology is being regularly updated (https://www.symplur.com/healthcare-hashtags/ ontology/urology/) and has been endorsed by key SoMe stakeholders. Use of these standardized hashtags is encouraged.

\section{Conclusions}

In summary, SoMe affords urologists novel tools for interacting with colleagues, crowdsourcing opinions, and staying updated with the latest discoveries and innovations. Indeed, SoMe is reshaping the way the urological care providers communicate. Barriers to professional SoMe are low, but appropriate engagement requires courtesy, professionalism, and honesty. Adherence to guidelines will help users harness the benefits of SoMe in a safe and effective manner.

Author contributions: Hendrik Borgmann had full access to all the data in the study and takes responsibility for the integrity of the data and the accuracy of the data analysis.

Study concept and design: Borgmann, Catto, Kutikov.

Acquisition of data: Borgmann, Kutikov.

Analysis and interpretation of data: Borgmann, Kutikov.

Drafting of the manuscript: Borgmann, Kutikov.

Critical revision of the manuscript for important intellectual content: Borgmann, Cooperberg, Murhpy, Loeb, N'Dow, Ribal, Woo, Rouprêt, Winterbottom, Wijburg, Wirth, Catto, Kutikov.

Statistical analysis: None.

Obtaining funding: None.

Administrative, technical, or material support: None.

Supervision: Kutikov.

Other: None.

Financial disclosures: None.

Funding/Support and role of the sponsor: None

\section{References}

[1] Farnan JM, Snyder Sulmasy L, Worster BK, et al. Online medical professionalism: patient and public relationships: policy statement from the American College of Physicians and the Federation of State Medical Boards. Ann Intern Med 2013;158:620-7.

[2] Loeb S, Catto J, Kutikov A. Social media offers unprecedented opportunities for vibrant exchange of professional ideas across continents. Eur Urol 2014;66:118-9.

[3] Katz MS. Social media and medical professionalism: the need for guidance. Eur Urol 2014;66:633-4.

[4] Roupret M, Morgan TM, Bostrom PJ, et al. European Association of Urology (@Uroweb) recommendations on the appropriate use of social media. Eur Urol 2014;66:628-32.

[5] Murphy DG, Loeb S, Basto MY, et al. Engaging responsibly with social media: the BJUI guidelines. BJU Int 2014;114:9-11.

[6] Kemp S. Global digital report 2018. We Are Social. January 30, 2018. https://wearesocial.com/blog/2018/01/global-digital-report-2018

[7] Loeb S, Bayne CE, Frey C, et al. Updated survey of social media use by members of the American Urological Association. Urology Practice 2015;2:138-43.

[8] Wilkinson SE, Basto MY, Perovic G, Lawrentschuk N, Murphy DG. The social media revolution is changing the conference experience: analytics and trends from eight international meetings. BJU Int 2015;115:839-46.

[9] Roberts MJ, Perera M, Lawrentschuk N, Romanic D, Papa N, Bolton D. Globalization of continuing professional development by journal 
clubs via microblogging: a systematic review. J Med Internet Res 2015;17:e103.

[10] Canvasser NE, Ramo C, Morgan TM, Zheng K, Hollenbeck BK, Ghani KR. The use of social media in endourology: an analysis of the 2013 World Congress of Endourology meeting. J Endourol 2015;29:615-20.

[11] Sternberg KM, Loeb SL, Canes D, Donnelly L, Tsai MH. The use of Twitter to facilitate sharing of clinical expertise in urology. J Am Med Inform Assoc 2018;25:183-6.

[12] Cardona-Grau D, Sorokin I, Leinwand G, Welliver C. Introducing the Twitter impact factor: an objective measure of urology's academic impact on Twitter. Eur Urol Focus 2016;2:412-7.

[13] Cress PE. Using altmetrics and social media to supplement impact factor: maximizing your article's academic and societal impact. Aesthet Surg J 2014;34:1123-6.

[14] Attai DJ, Cowher MS, Al-Hamadani M, Schoger JM, Staley AC, Landercasper J. Twitter social media is an effective tool for breast cancer patient education and support: patient-reported outcomes by survey. J Med Internet Res 2015;17:e188.

[15] Crowson MG, Tucci DL, Kaylie D. Hearing loss on social media: who is winning hearts and minds? Laryngoscope. In press. https://doi. org/10.1002/lary.26902.

[16] Loeb S, Stork B, Gold HT, et al. Tweet this: how advocacy for breast and prostate cancers stacks up on social media. BJU Int 2017;120:461-3.

[17] Prabhu V, Lee T, Loeb S, et al. Twitter response to the United States Preventive Services Task Force recommendations against screening with prostate-specific antigen. BJU Int 2015;116:65-71.

[18] Nason GJ, O'Kelly F, Kelly ME, et al. The emerging use of Twitter by urological journals. BJU Int 2015;115:486-90.

[19] Thangasamy IA, Leveridge M, Davies BJ, Finelli A, Stork B, Woo HH. International Urology Journal Club via Twitter: 12-month experience. Eur Urol 2014;66:112-7.

[20] Borgmann H, DeWitt S, Tsaur I, Haferkamp A, Loeb S. Novel survey disseminated through Twitter supports its utility for networking, disseminating research, advocacy, clinical practice and other professional goals. Can Urol Assoc J 2015;9:E713-7.

[21] Loeb S, Roupret M, Van Oort I, et al. Novel use of Twitter to disseminate and evaluate adherence to clinical guidelines by the European Association of Urology. BJU Int 2017;119:820-2.

[22] Adesoye T, Mangurian C, Choo EK, et al. Perceived discrimination experienced by physician mothers and desired workplace changes: a cross-sectional survey. JAMA Intern Med 2017;177:1033-6.

[23] Raviotta JM, Nowalk MP, Lin CJ, Huang HH, Zimmerman RK. Using Facebook to recruit college-age men for a human papillomavirus vaccine trial. Am J Mens Health 2016;10:110-9.

[24] Borgmann H, Kliesch S, Roth S, Roth M, Degener S. Feasibility and efficacy of a urologic profession campaign on cryptorchidism using internet and social media. Urol Int 2017;98:478-82.

[25] Koo K, Ficko Z, Gormley EA. Unprofessional content on Facebook accounts of US urology residency graduates. BJU Int 2017;119:955-60.

[26] Struck JP, Siegel F, Kramer MW, et al. Substantial utilization of Facebook, Twitter, YouTube, and Instagram in the prostate cancer community. World J Urol 2018;36:1241-6.
[27] Borgmann H, Salem J, Baunacke M, et al. Mapping the landscape of urology: a new media-based cross-sectional analysis of public versus academic interest. Int J Urol 2018;25:421-8.

[28] Dong C, Cheema M, Samarasekera D, Rajaratnam V. Using LinkedIn for continuing community of practice among hand surgeons worldwide. J Contin Educ Health Prof 2015;35:185-91.

[29] Loeb S, Bayne CE, Frey C, et al. Use of social media in urology: data from the American Urological Association (AUA). BJU Int 2014;113:993-8.

[30] Rivas JG, Socarras MR, Patruno G, et al. Perceived role of social media in urologic knowledge acquisition among young urologists: a European survey. Eur Urol Focus. In press. https://doi.org/10.1016/j. euf.2016.11.010.

[31] Dorfman RG, Vaca EE, Mahmood E, Fine NA, Schierle CF. Plastic surgery-related hashtag utilization on instagram: implications for education and marketing. Aesthet Surg J 2018;38:332-8.

[32] Chhabra N, Bryant SM. Snapchat toxicology: social media and suicide. Ann Emerg Med 2016;68:527.

[33] Mars M, Scott RE. WhatsApp in clinical practice: a literature review. Stud Health Technol Inform 2016;231:82-90.

[34] Sener TE, Buttice S, Sahin B, et al. WhatsApp use in the evaluation of hematuria. Int J Med Inform 2018;111:17-23.

[35] Wang W. The social media revolution in Chinese urology. BJU Int June 23, 2015. http://www.bjuinternational.com/bjui-blog/ the-social-media-revolution-in-chinese-urology/

[36] Kutikov A, Catto J. The platinum journal in the digital age: harnessing digital media to propel academic urology into the future. Eur Urol Today 2015;27:7.

[37] Loeb S, Katz MS, Langford A, Byrne N, Ciprut S. Prostate cancer and social media. Nat Rev Urol 2018;11:1.

[38] Cosco TD. Medical journals, impact and social media: an ecological study of the Twittersphere. CMAJ 2015;187:1353-7.

[39] Murphy D. PRECISION delivers on the PROMIS of mPMRI in early detection of prostate cancer. BJU Int March 19, 2018. http://www. bjuinternational.com/bjui-blog/precision-delivers-promis-mpmriearly-detection-prostate-cancer/

[40] Matta R, Doiron C, Leveridge MJ. The dramatic increase in social media in urology. J Urol 2014;192:494-8.

[41] Mayol J, Dziakova J. Value of social media in advancing surgical research. Br J Surg 2017;104:1753-5.

[42] Calopedos RJS, Garcia C, Rashid P, Murphy DG, Lawrentschuk N, Woo HH. Citation indices for social media articles in urology. BJU Int 2017; 119:47-52.

[43] Logghe H, Jones C, McCoubrey A, Fitzgerald E. \#ILookLikeASurgeon: embracing diversity to improve patient outcomes. BMJ 2017;359: j4653.

[44] Kutikov A, Woo HH, Catto JW. Urology tag ontology project: standardizing social media communication descriptors. Eur Urol 2016;69:183-5.

[45] Borgmann H, Katz MS, Catto J, Weight C, Kutikov A. Quantification of urology related twitter traffic activity through a standardized list of social media communication descriptors. Urology Practice 2017;4:349-54.

[46] Gill BC, Ericson KJ, Hemal S, Babbar P, Shoskes DA. The digital footprint of academic urologists: where do we stand? Urology 2016;90:27-31. 